\title{
VỀ BỘ QUY TẮC ỨNG XỬ VĂN HÓA CỦA NGƯỜI ĐÀ LẠT \\ Nguyễn Văn Nghiệp ${ }^{a^{*}}$, Trịnh Như Phong ${ }^{b}$
}

\author{
${ }^{a}$ Khoa Luật học, Truờng Đại học Đà Lạt, Lâm Đồng, Việt Nam \\ ${ }^{b}$ Truoòng Đại hoc Đà Lạt, Lâm Đồng, Việt Nam \\ "Tác giả liên hệ: Email: nghiepnv@dlu.edu.vn
}

\section{Lịch sử bài báo}

Nhận ngày 02 tháng 01 năm 2020

Chỉnh sửa ngày 07 tháng 02 năm 2020 | Chấp nhận đăng ngày 14 tháng 02 năm 2020

\section{Tóm tắt}

Nhằm giũ gìn và phát huy phong cách ngườ Đà Lạt "hiền hòa, thanh lịch, mến khách", bài báo trình bày nhũng nguyên tắc khi xây dụng Bộ quy tắc ứng xủ văn hóa của nguời Đà Lạt, một số nội dung của Bộ quy tắc ứng xủ và những khó khăn trong quá trình xây dựng và áp dụng Bộ quy tắc này.

Từ khóa: Bộ quy tắc; Phong cách người Đà Lạt; Ứng xử văn hóa.

DOI: http://dx.doi.org/10.37569/DalatUniversity.10.1.715(2020)

Loại bài báo: Bài báo nghiên cứu gốc có bình duyệt

Bản quyền @ 2020 (Các) Tác giả.

Cấp phép: Bài báo này được cấp phép theo CC BY-NC 4.0 


\title{
ABOUT DALAT'S CULTURAL NORMS
}

\author{
Nguyen Van Nghiep ${ }^{a^{*}}$, Trinh Nhu Phong ${ }^{\mathrm{b}}$ \\ ${ }^{a}$ The Faculty of Law, Dalat University, Lamdong, Vietnam \\ ${ }^{b}$ Dalat University, Lamdong, Vietnam \\ *Corresponding author: Email: nghiepnv@dlu.edu.vn
}

\author{
Article history \\ Received: January $2^{\text {nd }}, 2020$ \\ Received in revised form: February $7^{\text {th }}, 2020 \mid$ Accepted: February $14^{\text {th }}, 2020$
}

\begin{abstract}
In order to preserve and promote the "peaceful, elegant, and hospitable" style of Dalat people, the article presents the principles when grinding Dalat's cultural norms, some contents of the ministry, and difficulties in developing and applying this set of rules.
\end{abstract}

Keywords: Cultural conduct; Dalat style; Set of rules.

DOI: http://dx.doi.org/10.37569/DalatUniversity.10.1.715(2020)

Article type: (peer-reviewed) Full-length research article

Copyright $\odot 2020$ The author(s).

Licensing: This article is licensed under a CC BY-NC 4.0 


\section{SỬ CÀ̀N THIẾT XÂY DỰNG MộT Bộ QUY TĂC ỨNG XỬ VĂN HÓA CỦA NGƯời ĐÀ LẠT}

Trong xu thế hội nhập ngày nay, việc bảo tồn và phát huy những giá trị văn hóa là vấn đề mà Đảng, Nhà nước Việt Nam rất quan tâm. Nghị quyết 33/NQ-TW ngày 09 tháng 6 năm 2014 đã nhấn mạnh: "Xây dựng nền văn hóa và con người Việt Nam phát triển toàn diện, hướng đến chân-thiện-mỹ, thấm nhuần tinh thần dân tộc, nhân văn, dân chủ và khoa học" (Ban Chấp hành Trung ương, 2014). Chính vì vậy, thành phố Đà Lạt đã và đang đặt ra vấn đề tiếp tục xây dựng con người Đà Lạt trên cơ sở giữ gìn và phát huy phong cách "hiền hòa, thanh lịch, mến khách". Phong cách của người Đà Lạt đã tồn tại từ lâu và tạo nên nét đặc sắc cho Đà Lạt nhưng việc giữ gìn và phát huy phong cách ấy là việc không dễ trong quá trình phát triển. Do vậy, Nhóm nghiên cứu ${ }^{1}$ chúng tôi đã nghiên cứu và phác thảo Bộ quy tắc ứng xử văn hóa của người Đà Lạt trên cơ sở kế thừa và phát huy bản sắc văn hóa Đà Lạt, từ sự kết tinh hài hòa những phẩm chất tốt đẹp của con người giữa thiên nhiên tươi đẹp với tinh hoa văn hóa từ quê hương bản quán của cư dân nơi đây, nhằm góp phần cùng chính quyền và nhân dân địa phương trong việc giữ gìn và phát huy phong cách người Đà Lạt trong thời đại mới. Để hình thành nên Bộ quy tắc ứng xử văn hóa của người Đà Lạt (khi cần thiết, xin lược gọn là Bộ quy tắc) cần xuất phát từ các điều kiện tự nhiên và xã hội hình thành nên phong cách "hiền hòa, thanh lịch, mến khách". Phong cách ấy là sự tổng hòa và kết tinh từ các yếu tố chủ yếu sau: Các đặc điểm tự nhiên làm nên một "thiên đường nghỉ dưỡng" và tác động mạnh đến tính cách cư dân; Nguồn gốc và đặc điểm các nhóm cư dân trở thành chủ thể của một phong cách sống; Các yếu tố con người và văn hóa phương Tây tác động nhất định đến đời sống kinh tế-xã hội, văn hóa, và phong cách người Đà Lạt (Eric, 2015).

Trong nhịp sống sôi động của đất nước ngày càng phát triển, xu thế hội nhập đã làm cho Đà Lạt được bổ sung, đã và đang vươn tới một diện mạo mới. Với mục tiêu xây dựng thành phố Đà Lạt trở thành một thành phố thông minh, hiện đại, phát triển, và hội nhập nhưng vẫn giữ lại được những nét độc đáo của mình thì vấn đề giữ gìn bản sắc văn hóa và hình thành văn hóa mới là sự đòi hỏi tất yếu (Nguyễn, 2018). Do vậy, việc định hướng hành vi và bổ sung thêm phong cách văn minh, hiện đại của người Đà Lạt là điều mà toàn hệ thống chính trị và nhân dân luôn trăn trở. Và việc xây dựng một Bộ quy tắc không chỉ nhằm giữ gìn phong cách người Đà Lạt và phát huy phong cách ấy, mà còn phù hợp với xu thế chung và phát triển chính phong cách ấy. Qua khảo sát thực tế, nhóm nghiên cứu nhận thấy rằng việc xây dựng một Bộ quy tắc văn hóa ứng xử cho thành phố Đà Lạt là hết sức cần thiết, không đơn thuần xuất phát từ ý muốn của lãnh đạo hay ý chí chủ quan của người nghiên cứu, mà là nhu cầu khách quan từ tâm tư, nguyện vọng, và nhận thức của cư dân. Minh chứng thể hiện ở Bảng 1.

\footnotetext{
${ }^{1}$ Nhiệm vụ khoa học công nghệ: Giũ gìn và phát huy phong cách người Đà Lạt "hiền hòa, thanh lịch, mến khách”, Ủy ban Nhân dân thành phố Đà Lạt (Quản lý), Trường Đại học Đà Lạt (Chủ trì), Lê Hồng Phong (Chủ nhiệm), 2018-2020.
} 


\section{Bảng 1. Sự cần thiết xây dựng Bộ quy tắc ứng xử đối với thành phố Đà Lạt}

\begin{tabular}{lll}
\hline Sự cần thiết của Bộ quy tắc đối với Thành phố $(\mathrm{n}=76)$ & Tần số & Tỷ lệ $(\%)$ \\
\hline Điều chỉnh các ứng xử & 14 & 18.4 \\
Giúp du khách hiểu rõ hơn về con người Đà Lạt & 6 & 7.9 \\
Làm cho người dân trở nên thân thiện hơn & 1 & 1.3 \\
Tạo ấn tượng khác lạ với du khách & 2 & 2.6 \\
Tạo ra nét đặc trưng cho người Đà Lạt & 53 & 69.8 \\
Tổng & 76 & 100.0 \\
\hline
\end{tabular}

Nguồn: Số liệu điều tra của Nhóm nghiên cứu, 2019.

Tuy nhiên, không phải người dân nào cũng quan tâm đến một Bộ quy tắc như vậy. Khi hỏi cả du khách và người dân Đà Lạt "có biết đến Bộ quy tắc ứng xủ cho nguoòi Đà Lạt đã được thành phố công bố năm 2017 (có treo biển ở cây xăng Kim Cúc (cũ)) không?" thì có đến 1,124 người trả lời "không" (chiếm tỷ lệ $90.2 \%$ ), và chỉ có 122 người trả lời "có" (chiếm tỷ lệ 9.8\%) (Bảng 2).

Bảng 2. Biết về Bộ quy tắc ứng xử

\begin{tabular}{lll}
\hline Biết về Bộ quy tắc ứng xử & Tần số & Tỷ lệ (\%) \\
\hline Có & 122 & 9.8 \\
Không & 1,124 & 90.2 \\
Tổng & 1,246 & 100.0 \\
\hline
\end{tabular}

Nguồn: Số liệu điều tra của Nhóm nghiên cứu, 2019.

Có lẽ việc thừa nhận người Đà Lạt hiền hòa, thanh lịch, mến khách tuy không phải là tuyệt đối nhưng khá rõ ràng khi cả du khách và người dân đều thừa nhận khi được hỏi đến. Thế nhưng việc biết một Bộ quy tắc đã được chính quyền công bố thì đa số những người được hỏi không hề biểt. Dường như trong quá khứ và cho đến nay, người ta quan tâm đến phong cách trong chiều sâu tâm hồn và hành vi cư xử của người Đà Lạt hơn một Bộ quy tắc ứng xử mang tính văn bản hành chính của chính quyền. Đó cũng là khó khăn từ phía người nghiên cứu và phía cơ quan tham mưu hay tổ chức thực hiện. Tuy nhiên, số liệu trên cũng cho thấy cần tăng cường công tác tuyên truyền để người dân và du khách hiểu và hành động theo những quy tắc ứng xử mang tính chính thức chung cho cả công đồng cư dân Thành phố và cả những ai đến với Thành phố này. Chính người dân đã thấy rõ tầm quan trọng của Bộ quy tắc trong việc tạo ra đặc trưng cho người Đà Lạt, tần số tương đối là $53 / 76$ người trả lời, chiếm tỷ lệ $69.8 \%$ và điều chỉnh các ứng xử, tần số 14 , chiếm tỷ lệ $18.4 \%$. Ngoài ra nó cũng giúp du khách hiểu rõ hơn về con người Đà Lạt, tạo ấn tượng khác lạ với du khách và làm cho người dân trở nên thân thiện hơn (Bảng 3).

Bảng 3. Ý nghĩa của Bộ quy tắc đối với thành phố

\begin{tabular}{lll}
\hline Ý nghĩa của Bộ quy tắc đối với thành phố $(\mathrm{n}=76)$ & Tần số & Tỷ lệ $(\%)$ \\
\hline Điều chỉnh các ứng xử & 14 & 18.4 \\
Giúp du khách hiểu rõ hơn về con người Đà Lạt & 6 & 7.9 \\
Làm cho người dân trở nên thân thiện hơn & 1 & 1.3 \\
Tạo ấn tượng khác lạ với du khách & 2 & 2.6 \\
Tạo ra nét đặc trưng cho người Đà Lạt & 53 & 69.8 \\
Tổng & 76 & 100.0 \\
\hline
\end{tabular}

Nguồn: Số liệu điều tra của Nhóm nghiên cứu, 2019. 


\section{Bảng 4. Lý do không biết Bộ quy tắc}

\begin{tabular}{lll}
\hline Lý do không biết Bộ quy tắc $(\mathrm{n}=1019)$ & Tần số & Tỷ lệ $(\%)$ \\
\hline Chưa nghe qua & 120 & 11.8 \\
Hướng dẫn viên không thông báo & 29 & 2.8 \\
Không biết & 330 & 32.4 \\
Không cập nhật thông tin & 26 & 2.6 \\
Không đề ý & 375 & 36.8 \\
Không được phổ biến & 59 & 5.8 \\
Không quan tâm & 67 & 6.6 \\
Không thấy & 12 & 1.2 \\
Mới lên Đà Lạt & 1 & 0.1 \\
Tồng & 1,019 & 100.0 \\
\hline
\end{tabular}

Nguồn: Số liệu điều tra của Nhóm nghiên cứu, 2019.

Khi được hỏi lý do về việc không biết đến Bộ quy tắc, cả người dân và du khách cho rằng họ không để ý, chiếm tỷ lệ $36.8 \%$ cao nhất trong các câu trả lời, kế đến là không biết có Bộ quy tắc này, chiếm tỷ lệ $32.4 \%$, chưa nghe qua, không quan tâm, không thông báo... (Bảng 4).

\section{CÁC NGUYÊN TẮC KHI XÂY DỰNG BỘ QUY TĂC ỬNG XỦ̉ VĂN HÓA}

Trên cơ sở đã phân tích ở trên, để xây dựng Bộ quy tắc ứng xử văn hóa của người Đà Lạt, cần quán triệt các nguyên tắc trong quá trình từ xây dựng đến tổ chức thực hiện Bộ quy tắc ứng xử ấy. Theo đó, các nguyên tắc được đề cập là:

Một là, Bộ quy tắc ứng xử văn hóa của người Đà Lạt phải phù hợp với đường lối chủ trương của Đảng, pháp luật của Nhà nước về văn hóa. Nguyên tắc này có tính căn bản và bắt buộc, một mặt vừa thể hiện quan điểm của Đảng vừa cụ thể hóa những quy định của pháp luật về vấn đề văn hóa, bảo tồn và phát huy văn hóa; Mặt khác là việc điều chỉnh, định hướng hành vi ứng xử có văn hóa cho người dân thể hiện được đặc trưng riêng của Đà Lạt. Do vậy, Bộ quy tắc được xây dựng phải thể hiện những chuẩn mực mà trước tiên phải tuân thủ các quan điểm của Đảng, pháp luật của Nhà nước về văn hóa. Bộ quy tắc không được đi ngược lại lợi ích của Nhà nước, của xã hội và của nhân dân. Ngoài ra, việc xây dựng Bộ quy tắc ứng xử của người Đà Lạt cũng không được trái với các văn bản của Hội đồng nhân dân và Ủy ban Nhân dân tỉnh Lâm Đồng cũng như của thành phố Đà Lạt.

Hai là, Bộ quy tắc ứng xử văn hóa không vi phạm truyền thống đạo đức và những phong tục tập quán tốt đẹp của nhân dân. Đây là nguyên tắc nền tảng, đạo đức với ý nghĩa là cách thức, lối sống của các cá nhân trong xã hội buộc mọi người phải tự giác tuân theo. Vì vậy, khi xây dựng Bộ quy tắc phải đảm bảo không vi phạm truyền thống đạo đức của xã hội. Phong tục tập quán của một nhóm người, một cộng đồng dân cư, hay một dân tộc không phải là pháp luật, nó nhằm góp phần điều chỉnh hành vi nội bộ nhóm người, của cộng đồng dân cư hay của dân tộc đó. Do đó, tính quy phạm của phong tục tập quán hẹp hơn pháp luật về không gian và đối tượng tác động. Đà Lạt là địa bàn cộng cư của cư dân nhiều địa phương, nhiều dân tộc cùng sinh sống và làm việc. Vì vậy, để bảo đảm một Bộ quy tắc được xây dựng hoàn chỉnh và thực hiện một cách tương đối đầy đủ thì không được vi phạm truyền thống đạo đức nói chung, phong tục tập quán tốt đẹp của các dân tộc đang sinh sống và làm việc tại đây, để có thể vừa phát huy vừa gìn giữ, vừa bảo tồn, vừa phát triển đặc trưng văn hóa đa dạng của Đà Lạt trong tổng thể nên văn hóa Việt Nam tiên tiến, đậm đà bản sắc dân tộc. 
Ba là, Bộ quy tắc ứng xử văn hóa phải phù hợp với điều kiện tự nhiên, kinh tế, và xã hội của thành phố Đà Lạt. Đặc thù của Đà Lạt là một thành phố cao nguyên khí hậu mát mẻ quanh năm, địa hình đồi núi với những con đường uốn lượn ngay trong thành phố. Bên cạnh đó, Đà Lạt phát triển kinh tế bằng dịch vụ và du lịch, lượng khách du lịch đến thăm quan Đà Lạt ngày càng tăng. Hiện tại, thành phố Đà Lạt là thành phố duy nhất ở Việt Nam không có hệ thống đèn tín hiệu giao thông nên khi xây dựng Bộ quy tắc ứng xử văn hóa, đặc biệt là văn hóa tham gia giao thông đường bộ (văn hóa ứng xử trong giao thông) của người dân và $\mathrm{du}$ khách phải xác định đến những yếu tố này. Do vậy, Bộ quy tắc ứng xử văn hóa được xây dựng phải phù hợp với điều kiện tự nhiên, kinh tế, và xã hội thì mới có thể đi vào cuộc sống, xóa bỏ khoảng cách giữa lý thuyết và thực tiễn vẫn đặt ra đối với các công trình nghiên cứu.

Bốn là, phải đảm bảo tính dân chủ và nhân văn khi xây dựng và vận hành Bộ quy tắc. Nguyên tắc này nhằm đảm bảo Bộ quy tắc ứng xử không phải là sản phẩm của mệnh lệnh hành chính, không phải là luật pháp để bắt buộc người dân phải tuyệt đối phục tùng. Bộ quy tắc này được xây dựng trên cơ sở khách quan của điều kiện tự nhiên và con người, sự tự nguyện của cư dân Thành phố vì giá trị nhân văn và tính hợp lý, vì mục tiêu xây dựng thành phố Đà Lạt văn minh, hiện đại, thân thiện, mến khách. Bộ quy tắc nhân danh người Đà Lạt, cụ thể là ứng xử văn hóa của người Đà Lạt nhưng với mong mỏi có sự tán thành, hợp tác, tự giác tôn trọng và tuân thủ của du khách vì quyền lợi và sự hài lòng của chính du khách, không chỉ vì cuộc sống thành bình và hạnh phúc của cư dân Đà Lạt. Và với nguyên tắc dân chủ và nhân văn, để gìn giữ và phát huy phong cách người Đà Lạt thì việc phổ biến, tuyên truyền, nhắc nhở, khuyến cáo, biểu dương gương tốt, tạo đồng thuận... là biện pháp khởi đầu và thường xuyên trong suốt quá trình xây dựng thành phố, phát triển con người.

Mục đích đề cập đến các nguyên tắc khi xây dựng Bộ quy tắc là để cố gắng tạo ra tính chuẩn mực. Tính chuẩn mực của Bộ quy tắc đã được thể hiện ở những quy định chung để định hướng cho nhóm nghiên cứu khi xây dựng bộ quy tắc không vượt khỏi "đường ray" đã đặt ra. Bên cạnh đó, hy vọng Bộ quy tắc còn là sự hướng dẫn, điều chỉnh hành vi của mọi ngườinhững người sinh sống, làm việc, học tập, hay đến tham quan, du lịch ở Đà Lạt.

\section{NộI DUNG Bộ QUY TẮC ÚNG XỦ VĂN HÓA CỦA NGƯỜI ĐÀ LẠT}

Bộ quy tắc gồm ba chương, Chương Một là những quy định chung, nội dung của chương này gồm có phạm vi áp dụng, đối tượng áp dụng, và mục đích xây dựng Bộ quy tắc; Chương Ba là quy định về việc tổ chức triển khai thực hiện, với những quy định thể hiện trách nhiệm của cơ quan, tổ chức, và cá nhân trong việc tuyên truyền, thực hiện, và giám sát để Bộ quy tắc ứng xử văn hóa thực sự đi vào cuộc sống; Chương Hai là chương chính của Bộ quy tắc. Chương Hai trình bày nội dung ứng xử, giới thiệu những nguyên tắc ứng xử chung của người Đà Lạt, nhưng có chia thành những nhóm đối tượng khác nhau; Tùy thuộc vào vị trí chức năng nhiệm vụ của mình để những nhóm đối tượng đó phải ứng xử cho phù hợp. Cụ thể gồm: Nhóm cán bộ, công chức, viên chức; Nhóm học sinh, sinh viên; Nhóm chủ thể kinh doanh dịch vụ lưu trú; Nhóm bán hàng; Nhóm chủ thể kinh doanh dịch vụ ăn uống, nhà hàng; Nhóm du khách đến thăm quan Đà Lạt; Nhóm công dân khác. Nhóm cuối cùng chính là nhóm đông nhất tại nơi cư trú, mặc nhiên trong gia đình họ có thể đã bao hàm một số nhóm kia, song việc nhấn mạnh một số nhóm không hề nhằm đề cao hay coi nhẹ nhóm nào mà chỉ muốn gắn kết việc giữ gìn và phát huy 
phong cách người Đà Lạt với việc xây dựng một thành phố trọng điểm về du lịch, một thành phố thông minh, và hiện đại. Tất nhiên, trong bài viết này, cơ bản chúng tôi không đề cập đến vấn đề thành phố thông minh mà chỉ bàn về việc dự thảo một Bộ quy tắc ứng xử văn hóa. Bộ quy tắc này được xây dựng với phương châm "giữ gìn và phát huy phong cách người Đà Lạt, hiền hòa, thanh lịch, mến khách” (Trường Đại học Đà Lạt, 2018).

Hiền hòa là sự hiền lành, chan hòa, và hòa hợp của con người với con người, con người với thiên nhiên. Nét hiền hòa của người Đà Lạt được tạo nên từ môi trường sống có khí hậu trong lành và mát mẻ quanh năm, nên trong quá trình phát triển và hội nhập, dù có sự giao thoa văn hóa cũng không làm ảnh hưởng quá nhiều đến đời sống của con người Đà Lạt vốn rất hiền lành và thân thiện, trải qua cả trăm năm dường như vẫn yên bình, hiền hòa như vậy. Những người đến với Đà Lạt, với môi trường thiên nhiên ây hình như cũng trở nên hiền hòa và nhanh chóng thích nghi để phù hợp với không gian sống, nhịp điệu sống của cư dân thành phố. Tuy nhiên, hiền hòa không chỉ là hiền hậu và hiền lành, mà còn hài hòa với tự nhiên và xã hội, trong đó có thương yêu và tôn trọng con người, sẵn sàng giúp đỡ người khó khăn, kể cả với du khách.

Thanh lịch là một tính từ hàm chứa tính thanh nhã và tính lịch sự, lịch thiệp. Người thanh lịch là người thanh nhã trong cử chỉ, hành vi, nói năng, và sự lịch thiệp thể hiện ở cách ứng xử văn hóa, văn minh, và thân thiện. Người Đà Lạt không chỉ kế thừa văn hóa cổ truyền và tinh thần hiền dịu truyền thống, mà còn tiếp nhận và phát triển các yếu tố của nền văn hóa, văn minh phương Tây. Sự kết hợp của văn hóa phương Đông và phương Tây cũng góp phần tô đậm thêm nét thanh lịch trong phong cách người Đà Lạt. Từ đó hình thành nên những thú vui tao nhã như trồng hoa, chơi cây cảnh, chơi lan rất phong phú và đa dạng. Các khía cạnh có thể chưa đầy đủ nhưng cơ bản, được vận dụng khi dự thảo Bộ quy tắc với mong mỏi người Đà Lạt không chỉ tự bộc lộ sự thanh lịch nơi chính bản thân mình mà còn thể hiện trong quan hệ với người khác, trong mắt nhìn của người khác.

Mến khách là tính cách của người Đà Lạt xuất phát từ bản chất hiền hòa, thanh lịch thể hiện ở cách ứng xử thân thiện của người Đà Lạt, đồng thời đó cũng là đòi hỏi thực tế ở vùng đất này. Là một thành phố du lịch và nghỉ dưỡng, sự phát triển của Đà Lạt phụ thuộc rất nhiều vào việc kinh doanh các dịch vụ, đặc biệt là dịch vụ du lịch và lữ hành, nên sự mến khách không chỉ là tình cảm mà trở thành lẽ sống chính đáng. Nét đẹp này thể hiện ở những người bán hàng luôn tôn trọng và niềm nở với khách hàng, bán hàng không thách giá hay ép giá. Những người làm các dịch vụ khác không có thái độ bắt chẹt hay to tiếng với khách hàng. Đa số người Đà Lạt có cái nhìn thiện cảm, không soi mói, ganh tị, và sẵn sàng giúp đỡ, chỉ dẫn khi có người cần hỏi thăm, nhờ chỉ dẫn...

Sự hiền hòa, thanh lịch, mến khách đã được nhóm nghiên cứu thể hiện rõ trong bộ câu hỏi phỏng vấn các đối tượng cư dân cũng như trong khi dự thảo Bộ quy tắc ứng xử như: Nếu cán bộ, công chức, viên chức nói chung phải tuân thủ những nguyên tắc làm việc và ứng xử do pháp luật quy định, tuân thủ thêm các nội quy về văn hóa công sở do cơ quan quy định thì cán bộ, công chức, viên chức Đà Lạt phải ăn mặc lịch sự, có lời nói phải nhẹ nhàng, phục vụ tận tâm; Học sinh, sinh viên ngoài việc tuân thủ quy chế và nội quy về văn hóa học đường, còn phải có sự kính trọng lễ phép, biết nói lời hay ý đẹp...; 
Người bán hàng luôn tôn trọng khách, nói năng nhỏ nhẹ, luôn sẵn sàng giúp đỡ khi du khách và người dân cần...

Những nội dung "nên" và "không nên" trong bản dự thảo Bộ quy tắc không chỉ căn cứ các nguyên tắc (như đã nêu ở mục 2), cũng như không chỉ tuân thủ phương châm gìn giữ và phát huy phong cách người Đà Lạt (như vừa trình bày ở mục 3 ) mà còn dựa trên cơ sở điều tra khảo sát tại địa bàn Thành phố và được tổng hợp ở Bảng 5.

\section{Bảng 5. Đánh giá các biểu hiện của phong cách hiền hòa, thanh lịch, mến khách}

\begin{tabular}{|c|c|c|c|c|c|c|c|}
\hline \multirow{2}{*}{\multicolumn{2}{|c|}{$\begin{array}{l}\text { Biểu hiện phong cách hiền hòa, thanh lịch, mến khách } \\
\text { của người Đà Lạt }\end{array}$}} & \multicolumn{5}{|c|}{ Mức độ đồng ý } & \multirow[b]{2}{*}{ Tổng } \\
\hline & & \multirow{2}{*}{$\begin{array}{l}\begin{array}{l}\text { Rất không } \\
\text { dồng ý }\end{array} \\
6\end{array}$} & \multirow{2}{*}{$\begin{array}{l}\begin{array}{l}\text { Không } \\
\text { dồng ý }\end{array} \\
65\end{array}$} & \multirow{2}{*}{$\begin{array}{l}\text { Phân vân } \\
225\end{array}$} & \multirow{2}{*}{$\begin{array}{l}\text { Đồng ý } \\
519\end{array}$} & $\begin{array}{l}\text { Rất } \\
\text { đồng ý }\end{array}$ & \\
\hline \multirow{2}{*}{ Tính tình hiền dịu, ôn hòa, dễ gần } & Tần số & & & & & 431 & 1246 \\
\hline & Tỷ lệ (\%) & 0.5 & 5.2 & 18.1 & 41.7 & 34.6 & 100.0 \\
\hline \multirow{2}{*}{$\begin{array}{l}\text { Không gây gổ, cãi cọ, không làm mất lòng } \\
\text { người khác }\end{array}$} & Tần số & 0 & 50 & 283 & 594 & 319 & 1246 \\
\hline & Tỷ lệ (\%) & 0.0 & 4.0 & 22.7 & 47.7 & 25.6 & 100.0 \\
\hline \multirow{2}{*}{ Đánh giá chung nhất về mức độ hiền hòa } & Tần số & 15 & 66 & 250 & 636 & 279 & 1246 \\
\hline & Tỷ lệ (\%) & 1.2 & 5.3 & 20.1 & 51.0 & 22.4 & 100.0 \\
\hline \multirow{2}{*}{ Thích đi nghe nhạc phòng trà } & Tần & 19 & 166 & 483 & 401 & 174 & 1243 \\
\hline & Tỷ lệ (\%) & 1.5 & 13.4 & 38.9 & 32.3 & 14.0 & 100.0 \\
\hline \multirow{2}{*}{$\begin{array}{l}\text { Chế biến món ăn đơn giản nhưng bắt mắt, } \\
\text { hấp dẫn, và tinh tế }\end{array}$} & & 16 & 117 & 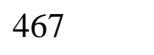 & & 208 & 1246 \\
\hline & Tỷ & 1.3 & 9.4 & 3 & & 16.7 & 100.0 \\
\hline \multirow{2}{*}{$\begin{array}{l}\text { Không nhậu nhẹt, say xỉn, không to tiếng, ồn } \\
\text { ào với người xung quanh }\end{array}$} & Tầr & 6 & 100 & 521 & 470 & 148 & 1245 \\
\hline & Tỷ lệ (\%) & 0.5 & 8.1 & 41 & 37.8 & 11.9 & 100.0 \\
\hline \multirow{2}{*}{$\begin{array}{l}\text { Trang phục nhã nhặn, lịch sự, không phản } \\
\text { cảm, diêm dúa }\end{array}$} & Tần số & 14 & 67 & & & 334 & 1245 \\
\hline & Tỷ & 1.1 & 5.4 & 2 & 4 & 26.8 & 100.0 \\
\hline \multirow{2}{*}{$\begin{array}{l}\text { Phụ nữ trang điểm nhẹ nhàng, tôn vinh vẻ } \\
\text { đẹp dịu dàng }\end{array}$} & Tầr & 9 & 64 & 262 & 5 & 315 & 1244 \\
\hline & Tỷ lệ (\%) & 0.7 & 5.1 & 21.1 & 47.7 & 25.3 & 100.0 \\
\hline \multirow{2}{*}{$\begin{array}{l}\text { Nhà ở thiết kế trang nhã, phù hợp với cảnh } \\
\text { quan, tôn trọng tự nhiên }\end{array}$} & Tần số & 9 & 73 & & 5 & 256 & 1244 \\
\hline & Tỷ & 0.7 & 5.9 & 28 & 44.6 & 20.6 & 100.0 \\
\hline \multirow{2}{*}{ Trang trí nội thất đơn giản, tao nhã, lịch sự } & Tần số & 6 & 81 & 361 & 558 & 239 & 1245 \\
\hline & Tỷ lệ (\%) & 0.5 & 6.5 & 29.0 & 44.8 & 19.2 & 100.0 \\
\hline \multirow{2}{*}{ Hưởng ứng các buổi sinh hoạt cộng đồng } & Tần & 12 & 90 & 444 & 521 & 178 & 1245 \\
\hline & Tỷ & 1.0 & 7.2 & 35.7 & 41.8 & 14.3 & 100.0 \\
\hline \multirow{2}{*}{$\begin{array}{l}\text { Văn hóa nhường đường khi tham gia giao } \\
\text { thông }\end{array}$} & Tần số & 14 & 98 & 431 & 550 & 152 & 1245 \\
\hline & Tỷ lệ (\%) & 1.1 & 7.9 & 34.6 & 44.2 & 12.2 & 100.0 \\
\hline \multirow{2}{*}{ Đánh giá chung nhất về sự thanh lịch } & Tần số & 9 & 54 & 358 & 596 & 229 & 1246 \\
\hline & Tỷ lệ (\%) & 0.7 & 4.3 & 28.7 & 47.8 & 18.4 & 100.0 \\
\hline \multirow{2}{*}{$\begin{array}{l}\text { Giao tiếp nhẹ nhàng, lịch thiệp, tế nhị, chân } \\
\text { thành }\end{array}$} & Tần số & 18 & 61 & 285 & 537 & 345 & 1246 \\
\hline & Tỷ lệ (\%) & 1.4 & 4.9 & 22.9 & 43.1 & 27.7 & 100.0 \\
\hline \multirow{2}{*}{ Úng xử thân thiện và lịch sự với khách } & Tần số & 11 & 53 & 305 & 557 & 319 & 1245 \\
\hline & Tỷ lệ (\%) & 0.9 & 4.3 & 24.5 & 44.8 & 25.6 & 100.0 \\
\hline \multirow{2}{*}{$\begin{array}{l}\text { Sẵn lòng giúp đỡ người khác/người lạ một } \\
\text { cách vô tư }\end{array}$} & Tần số & 19 & 87 & 370 & 507 & 262 & 1245 \\
\hline & Tỷ lệ (\%) & 1.5 & 7.0 & 29.7 & 40.7 & 21.1 & 100.0 \\
\hline \multirow{2}{*}{$\begin{array}{l}\text { Buôn bán không lợi dụng khách để chặt chém } \\
\text { hay nói thách giá cả hàng hóa }\end{array}$} & nTần số & 18 & 137 & 434 & 508 & 149 & 1246 \\
\hline & Tỷ lệ (\%) & 1.4 & 11.0 & 34.8 & 40.8 & 12.0 & 100.0 \\
\hline \multirow{2}{*}{ Đánh giá chung nhất về sự mến khách } & Tần số & 4 & 54 & 295 & 663 & 230 & 1246 \\
\hline & Tỷ lệ (\%) & 0.3 & 4.3 & 23.7 & 53.2 & 18.5 & 100.0 \\
\hline
\end{tabular}

Nguồn: Số liệu điều tra của Nhóm nghiên cứu, 2019. 


\section{NHŨN KHÓ KHĂN KHI DỬ THẢO VÀ THỰC HIÊ̂N BỘ QUY TẮC ỨNG XỬ VĂN HÓA}

Trong quá trình xây dựng Bộ quy tắc ứng xử chúng tôi luôn nhận được sự chỉ đạo, quan tâm, động viên, và tạo mọi điều kiện giúp đỡ của Thành ủy, Ủy ban Nhân dân thành phố Đà Lạt, và các phòng chức năng. Bên cạnh đó, người dân và du khách đến Đà Lạt đã thể hiện sự chân thành và sẵn sàng giúp đỡ nhóm nghiên cứu khi tiến hành điều tra, khảo sát, cũng như tạo mọi điều kiện cho nhóm nghiên cứu đạt được kết quả cao nhất. Những người biên soạn mong muốn Bộ quy tắc sẽ góp phần định hướng hành vi, hoàn thiện phong cách ứng xử văn hóa hiền hòa, thanh lịch, mến khách của người Đà Lạt, sẽ trở thành thói quen của mỗi con người cũng như du khách đến Đà Lạt, qua đó lan tỏa cốt cách của con người Đà Lạt. Tuy nhiên, chúng tôi nhận thấy có những khó khăn nhất định khi soạn thảo và dự liệu những vướng mắc khi triển khai thực hiện như sau:

- Thứ nhất, Bộ quy tắc liên quan đến cách ứng xử văn hóa nên khi xây dựng vẫn còn nhiều vấn đề mà nhóm nghiên cứu băn khoăn có nên đưa vào hay không, nếu đưa vào thì có phù hợp hay không? Cái gì nên làm, cái gì không nên làm... Nếu đưa vào tuy không sai nhưng sẽ làm cho Bộ quy tắc nặng nề, rườm rà, khó nhớ, khó thực hiện, thậm chí trùng với các nội quy, quy định về văn hóa công sở, văn hóa học đường...

- Thư hai, Bộ quy tắc chỉ định hướng, hướng dẫn, và khuyến khích người dân nên làm hoặc không nên làm chứ không phải là văn bản quy phạm pháp luật, khi có vi phạm cũng không có chế tài để xử lý.

- Thứ $b a$, nếu Bộ quy tắc được thông qua thì việc tổ chức thực hiện cũng có thể gặp những khó khăn như: Cơ quan nào chịu trách nhiệm tuyên truyền, phổ biến, và triển khai thực hiện và cơ quan nào kiểm tra giám sát hoặc khi triển khai có thể vấp phải ý kiến chưa đồng thuận của một số người dân... Và nếu các khu dân cư chưa được bàn bạc, thảo luận để biết và góp thêm ý kiến hoàn thiện, để hiểu và cộng cảm, chia sẻ, thực hiện thì sản phẩm cũng chỉ là dự thảo mang tính học thuật của các nhà nghiên cứu hoặc chỉ là văn bản hành chính mang tính quan phương.

- Thư tur, Đà Lạt vốn là thành phố du lịch nổi tiếng, khách du lịch đến từ mọi miền đất nước và từ các nước khác trên thế giới. Mỗi vùng miền, khu vực lại có văn hóa ứng xử khác nhau nên Bộ quy tắc ứng xử dành cho Đà Lại chưa chắc phù hợp với văn hóa của họ nên cũng chỉ mang tính khuyến khích, đề nghị một sự hợp tác và chia sẻ.

- Thứ năm, thành phố Đà Lạt là một trung tâm học tập và nghiên cứu, nơi đây tập trung nhiều trường đại học, cao đẳng, và các viện nghiên cứu; Có hàng chục ngàn sinh viên từ mọi miền Tổ quốc đến nghiên cứu và học tập, và tất yếu họ sẽ mang theo văn hóa, ứng xử và phong tục tập quán của các địa phương mình đến Đà Lạt. Thêm vào đó giới trẻ ngày nay du nhập, học tập rất nhanh những phong cách ứng xử và chịu ảnh hưởng bởi “văn hóa mạng”. 
Điều đó sẽ ảnh hưởng không nhỏ đến văn hóa ứng xử và hiện tượng "pha loãng” phong cách của người Đà Lạt vốn hiền hòa, thanh lịch, mến khách.

- Thứ sáu, khi Bộ quy tắc này được triển khai có thể có bộ phận cư dân không thực hiện những nội dung nào đó trong quy tắc, bởi cách ứng xử đã gắn với họ từ rất lâu, đã ăn sâu vào tiềm thức của mỗi người, để thay đổi suy nghĩ là một vấn đề hết sức khó khăn và là một quá trình lâu dài. Tìm ra cách thức để dần dần chuyển biến phong cách ứng xử của những người này đòi hỏi phải có sự quyết tâm cao của các cơ quan ban ngành trên địa bàn Thành phố và cũng là điều nhóm nghiên cứu chúng tôi quan ngại.

\section{THAY LỜI KẾT}

Trên đây là những vấn đề liên quan đến Bộ quy tắc ứng xử của người Đà Lạt mà nhóm nghiên cứu sơ bộ dự thảo. Để Bộ quy tắc ứng xử thực sự đi vào cuộc sống cần phải có sự quyết tâm cao của cả hệ thống chính trị Thành phố; Quan trọng hơn, rất cần có sự đồng tình, cộng cảm, cộng đồng trách nhiệm một cách tự nguyện của tất cả người dân sinh sống và làm việc tại Đà Lạt và của cả du khách, sao cho mỗi cá nhân, mỗi tổ chức là một tấm gương trong ứng xử văn hóa theo phong cách hiền hòa, thanh lịch, mến khách. Có như vậy thì các hành vi ứng xử mới góp phần vào việc gìn giữ và phát huy phong cách hiền hòa, thanh lịch, mến khách của người Đà Lạt; Góp phần xây dựng thương hiệu du lịch Đà Lạt; Xây dựng thành phố Đà Lạt thông minh và hiện đại trong xu thế hội nhập và phát triển bền vững của Việt Nam và khu vực.

\section{TÀI LIỆU THAM KHẢO}

Ban Chấp hành Trung ương. (2014). Nghị quyết số 33-NQ/TW về xây dựng và phát triển văn hóa, con người Việt Nam đáp úng yêu cầu phát triển bền vững đất nuớc. Hà Nội, Việt Nam.

Erict, J. (2015). Đỉnh cao đế quốc-Đà Lạt và sự hưng vong của Đông Dương thuộc Pháp (V. P. Phạm, \& T. C. Bùi, Dịch). Hà Nội, Việt Nam: NXB. Hồng Đức.

Nguyễn, V. N. (2018). Đà Lạt một thời hương xa. TP. Hồ Chí Minh, Việt Nam: NXB. Trẻ.

Trường Đại học Đà Lạt. (2018). Kỷ yếu Hội thảo khoa học: Giũ gìn và phát huy phong cách người Đà Lạt "hiền hòa, thanh lịch, mến khách". Lâm Đồng, Việt Nam. 